\title{
Developmental Trends in the SA-6 (2K12 KUB) Air Defence Missile Systems and the Finalized Developments in the Hungarian Air Force Surface-To-Air Missile System
}

\author{
BOZSÓKI Attila ${ }^{1}$
}

\begin{abstract}
Nowadays only a small number of governments can afford to spend money in the billions from their budgets to replace their surface-to-air defence systems. One of the reasons is the financial crises of the last decade that swept the world, but it is not the only one. Many governments decided to operate their outdated systems and try to improve their present capabilities, instead of obtaining newer ones. And to be honest, currently in Europe no countries have to be frightened or threatened by their neighbours. That is why they think it is enough to improve their existing systems - given adequate defence - rather than buying expensive new ones. On the other hand, it is less expensive to utilize soldiers who are currently trained to operate these types of equipment, than to teach them the operation of new types of equipment.
\end{abstract}

Keywords: air defence system, SA-6, Gainful, Strait Flush, missile, development

\section{Introduction}

The whole SA-6 air defence missile system was improved by Soviet engineers during the Cold War era of the 1960s. The first impressions were given to the world during the Yom Kippur conflict of 1973. Pilots gave it the nickname "three fingers of death" out of respect for the entire system. After that, the SA-6 systems spread within the Warsaw Pact countries, in Africa and in Asia as well. [1] Those countries had some different expectations and that is why so many variants of the original system exist all around the world. The developments of these also tend to vary.

\section{Developments in Iraq}

One of these occurred during Operation Iraqi Freedom in 2003, when a most interesting "in-digenous hybridisation of the $3 M 9 S A M^{2}$ round with a seeker section from the Molniya/Vym-pel R-60 / AA-8 Aphid heat seeking air-to-air missile" [1: 45] was found (see Picture 1).

1 bozsoki.attila@gmail.com; Hungarian Air Force, Surface-To-Air Missile Wing 12 $2^{\text {th } ~ “ A r r a b o n a ”, ~ G y o ̋ r, ~}$ Hungary

2 SAM - Surface-to-Air Missile 


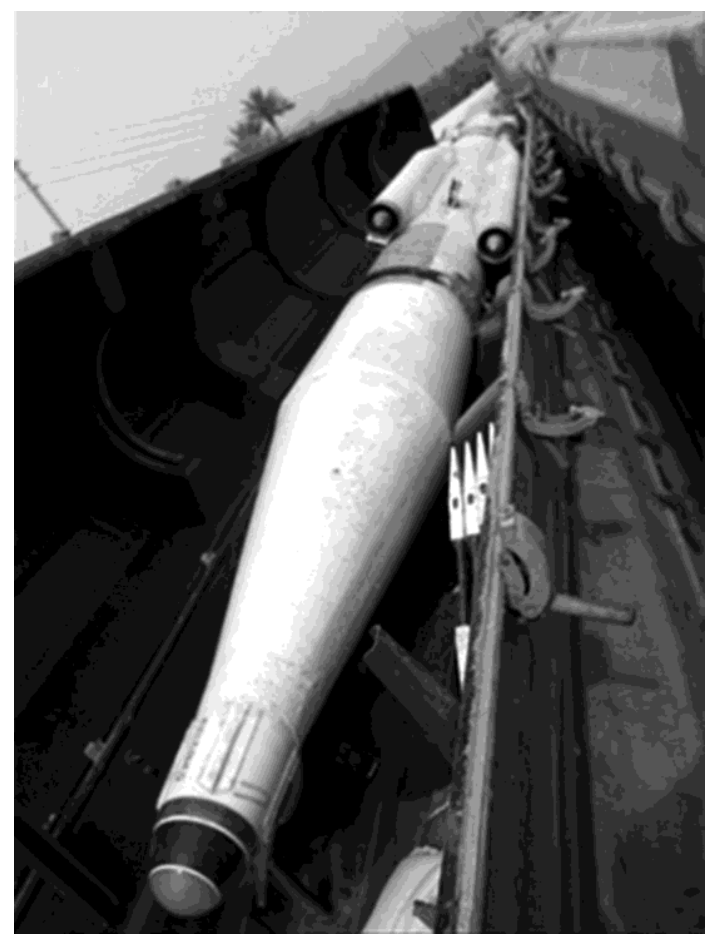

Picture 1. A captured Iraqi 3M9/R-60 hybrid heat seeking Gainful round can be seen. Note the Magnesium Fluoride nose window and ad hoc removal of the fixed nose strakes (US DoD image). [1: 46]

"While the resulting heat seeking 3M9 round would retain similar susceptibility to flares or more recently, infrared jammers, the missile engagement sequence would be devoid of the $C W^{3}$ illumination for the terminal phase of the missile's flight. As a result, the aircraft under attack would only have the command uplink signals and terminal phase 1S91 tracking signals to warn of an approaching missile. Where the defensive countermeasures suite relies on the CW signal to trigger angle/Range jamming, the heat seeking $3 M 9$ could be potentially very effective. ” [1: 45]

As this attempt shows, engineers in less developed countries were able to rebuild a sur- face-to-air missile, and mix its capability with another one to create an entirely new capa- bility, which makes it more dangerous, mainly when no one is expecting this type of variant from the original one. We do not know how advanced the missile was or if it was used during Operation Iraqi Freedom. Nor do we know how effective it was, but observations show that air crews, of any type of airplane, will not be as safe anymore. The pilots cannot rely on their aircraft rebuilt equipment, which earlier was suitable against "normal" SA-6 missiles they must now count on new options, as well.

$3 \mathrm{CW}$ - Continuous Wave 


\section{Changes in Romania}

Not just in Iraq, but also in Romania, officers and engineers are thinking about the develop- ment of SA-6 systems. Romania has many different types of - long, medium, short, very short range - air defence systems. They categorise the SA-6 into the medium range catego- ry, and they think it is worth improving its capability along with other ones. " $A$ more efficient option would be the ESSM ${ }^{4}$, a recent development of Kongsberg, which besides its superior performance has an advantage. In fact, the SA-6 system can be modernised at the same time with the same missile (similar project was proposed by the Polish producer WZU and Raytheon)'" [2: 110] Picture 2 shows the parameters of different types of air defence systems (distance, altitude, efficiency with one missile).

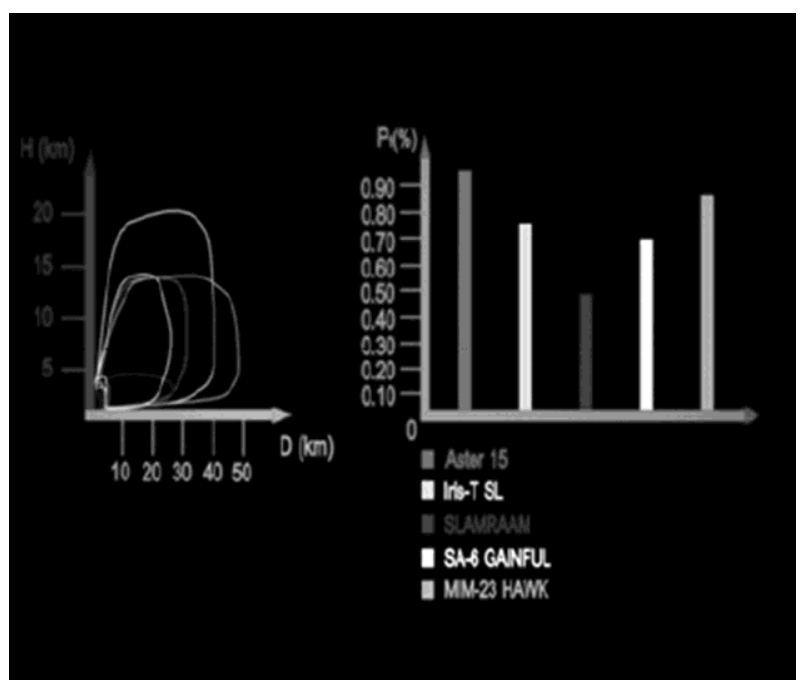

Picture 2. Capabilities of the Medium Range Air Defence (MRAD) [2: 110]

Three different types of missiles are loaded on an SA-6 2P25 launcher. From left to right in Picture 3 is the ESSM, Spyder-MR, 3M9. These attempts are shown in different countries as engineers try to solve a similar problem. Sometimes solved in similar and sometimes in different ways. They try to reduce the needed budget and get an effective and affordable solu- tion. They emphasize the reliability of the original system and the relatively fast opportunity to rebuild these pieces of equipment.

4 ESSM — Evolved SeaSparrow Missile, www.youtube.com/watch?v=pJeXesbbVGg, (downloaded: 1102 2014) 


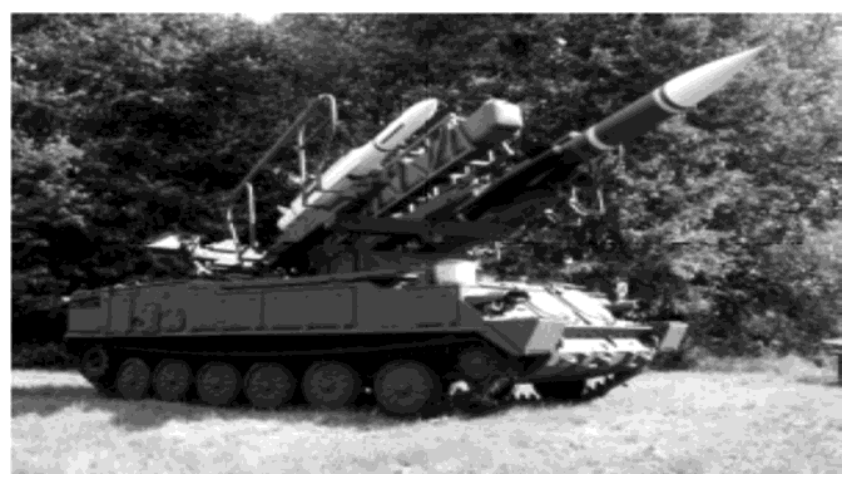

Picture 3. The modernization of the SA-6 system [2: 110]

\section{Ambitions in the Czech Republic}

The Czech Retia Company and the French MBDA 5 Company offer another modernised SA-6 system with renewed Straight Flush radar, in which almost the whole system - the surveillance and fire control radar electronics, target illuminator - have been upgraded and now have a new communication system and new operators' workstations too. Additionally, the whole system is operated with Aspide 2000 missiles (see Picture 4). Unfortunately this improvement is solved with some disadvantages. The intercept coverage is only 23 kilome- tres while the original was about 27 kilometres in distance. The renewed system is able to track, intercept and engage the target from 25 metres up to 12 kilometres from the original

14 kilometres in altitude. And the main problem with the Aspide 2000 missile is that it is able to fly only at 1.8 Mach while the original 9M9 missile is able to fly at $2.8 \mathrm{Mach}$. And to be honest there is a very big difference between the two systems, which gives the advantage to the original Soviet made system.

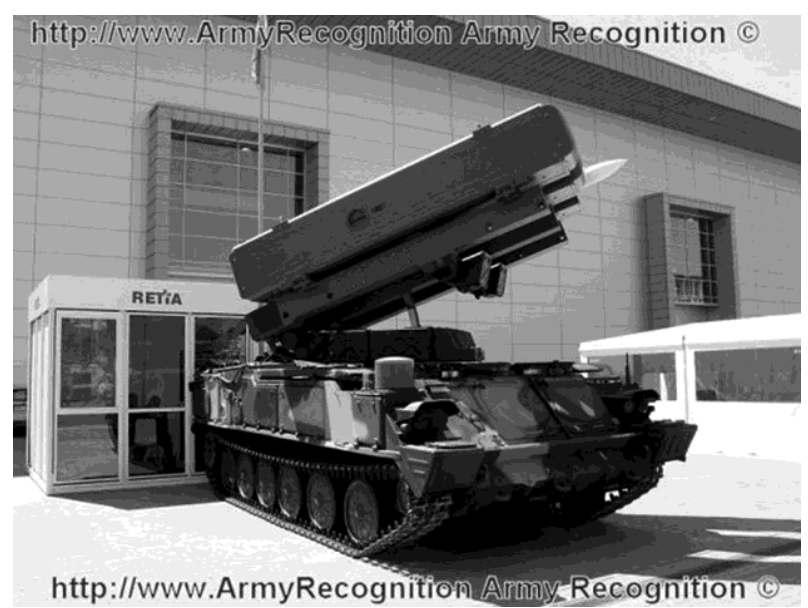

Picture 4. Modernised SA-6 2K12 KUB CZ [3]

5 MBDA - Matra BAE Dynamics Alenia 


\section{Trends in Hungarian Air Defence SA-6 Missile Systems}

The modernisation of Hungarian Air Force capabilities started in the middle 1990s. After the collapse of the Warsaw Pact, East European countries tried to solve their military defence problems. Earlier — during the Warsaw Pact era — all countries had their independent and Warsaw Pact integrated air defence systems. As the Cold War situation melted, Hungarian politicians and military experts decided to reduce the Hungarian air defence capabilities. First, they reduced the army organic air defence artillery, secondly, the home air defence mis- sile capabilities were eliminated stepby-step, and later the army organic air defence missile units were integrated into one. So nowadays, only HUAF ${ }^{6}$ Surface- $^{-}$ To-Air Missile Wing $12^{\text {th }}$ "Arrabona” exists in Györ.

The Hungarian SA-6 weapon system modernisation was fulfilled in 2002 in Poland and in 2003 in Hungary [4]. The Polish WZU-27 Company [5] renewed the Straight Flush radar stations and the Hungarian ARZENÁL Company [6] renewed 2P25 launchers. The main effects of the modernisation and overhaul of this weapon system are as follows:

- "Increased resistance to passive and active interference;

- Increased detection of low radar cross-section targets;

- Passive day and night target acquisition with long range thermo visual and television cameras;

- Application of IFF (target identification) system (Mark XII Mode 4) standard);

- Use of advanced spare parts allowing the supply of replacement spare parts necessary for normal operations;

- Introduction of advanced methods and algorithms for digital data processing,

- Enhanced radio electronic camouflage ECCM by application of radar sector blinking system;

- Elimination of adjustments and tuning for upgraded systems;

- Growth capability to launch state-of-the-art (fire and forget) missiles;

- Integration of dehumidification system;

- Air conditioned crew cabin." [4: 643] Visible changes are seen in

Pictures 5-8.

\footnotetext{
HUAF - Hungarian Air Force

WZU — Wojskowe Zakłady Uzbrojenia S. A.

IFF - Identification Friend or Foe
}

ECCM - Electronic Counter Countermeasures 


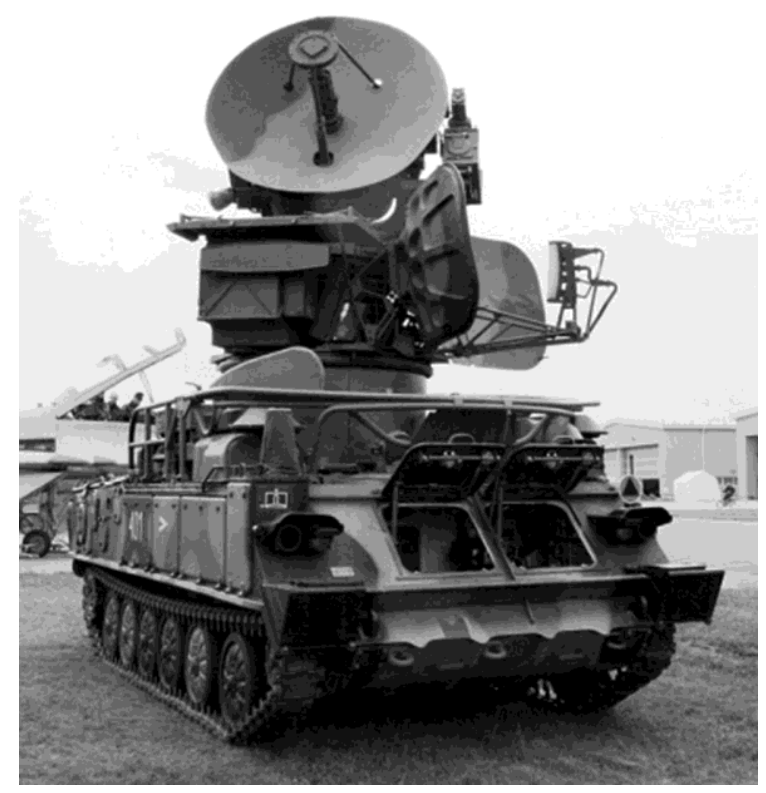

Picture 5. Hungarian Army 1S91 Straight Flush. A Polish built WZU-2 day/night optical tracker has been retrofitted on the RHS of the illuminator antenna (image (C) Miroslav Gyürösi). [1: 51]

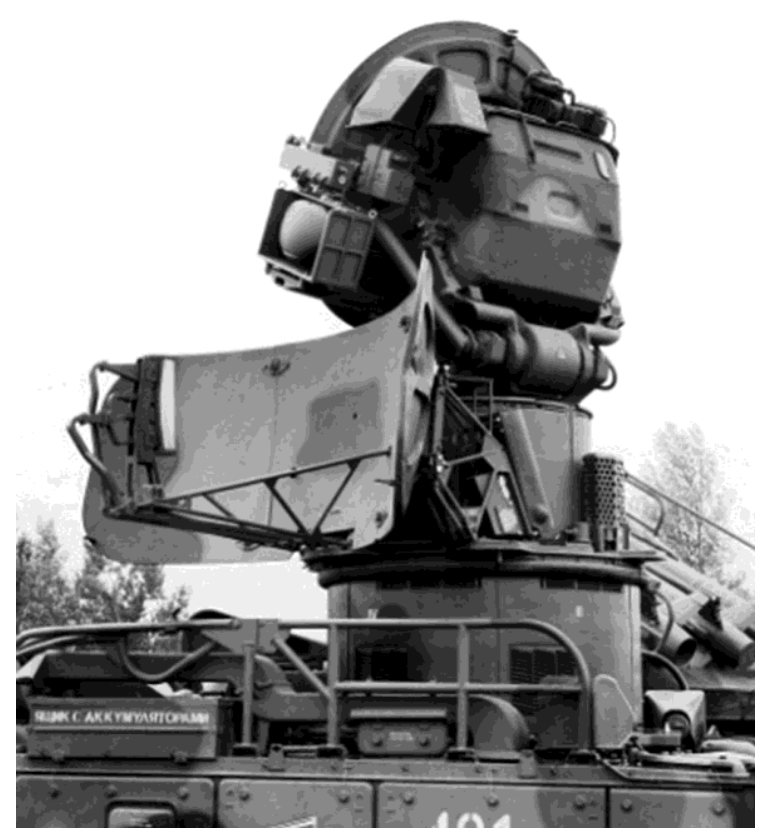

Picture 6. Hungarian Army 1S91 Straight Flush. Note the stacked feeds on the search radar (image (C) Miroslav Gyürösi). [1: 52] 


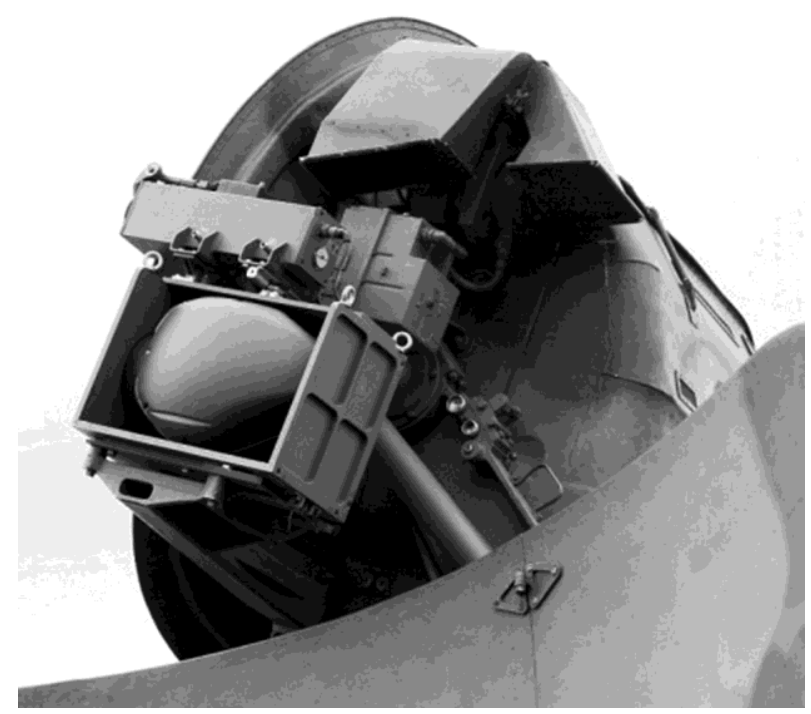

Picture 7. Hungarian Army 1S91 Straight Flush illuminator and optical tracker (image C Miroslav Gyürösi). [1: 53]

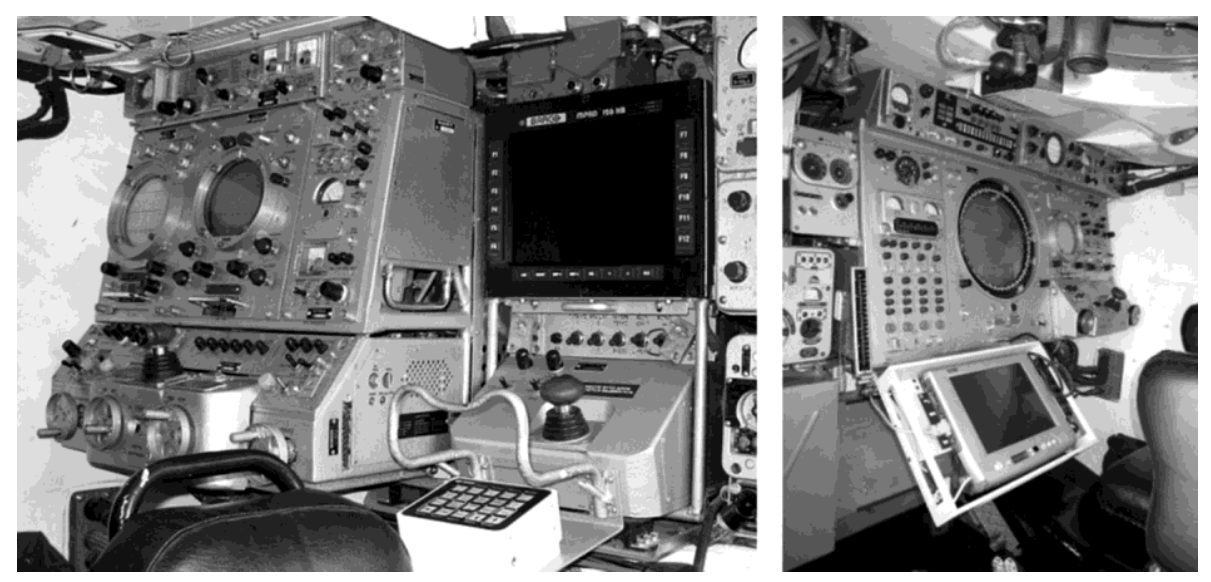

Picture 8. Hungarian Army 1S91 Straight Flush operator stations. Note the retrofitted digital flat panel displays provided by Hungarian contractor ARZENAL (image (C) Miroslav Gyürösi). [1: 54-55]

After the completion of the fire unit-level modernization, the Hungarian ARZENÁL Company commenced to renew the former Soviet K-1M SAM unit command post to a K-1P digitalized Wing/Group level Fire Distribution Centre. The $\mathrm{K}-1 \mathrm{M}$ was able to receive orders from higher echelon and send them to subunits but it was not able to get RAP ${ }^{10}$. It just used local radar signals as $\mathrm{LAP}^{11}$. That is why combat operations were based on local sensors data. [4]

10 RAP - Recognized Air Picture

11 LAP — Local Air Picture 
By that time Hungary had become a NATO ${ }^{12}$ member country, this development had to be able to solve NATO requirements. All air defence missile action had to be taken according to NATINADS ${ }^{13}$ rules and procedures. Thus the new $\mathrm{K}-1 \mathrm{P}$ was designed and built to meet these fire control requirements.

Functioning as an $\mathrm{FDC}^{14}, \mathrm{~K}-1 \mathrm{P}$ collects all relevant information and orders RAP from higher echelon and LAP from local sensors. The hardware and software correlates RAP and LAP and using its optimized algorithm, gives a recommendation on fire distribution for the authorised person - so called FDO $^{15}$ - and the FDC sends information back to $\mathrm{CRC}^{16}$, as well. The FDC links up to the higher echelon via NATO standard LINK-11B protocol. It is able to lead subordinated fire units providing them with the RAP and different orders and receives reports using $\mathrm{TCP}^{17}$, too. "A three-workplace computer system has been installed for handling fire distribution algorithm, for sensor management tasks and logistic support necessary for efficient work.” [4: 639] (In Picture 9 you can see the inside of $\mathrm{K}-1 \mathrm{P}$.) The orders and reports are delivered and sent via encrypted lines on wire or on radio connection. Additionally it is able to turn Straight Flash targeting radar and launchers towards the target. So fire units are able to lock on their targets without emission with their television or thermal cameras. They just turn on the target illumination radar when they have got an engagement order. The time of switching on depends on the type of missiles'. If the fire unit is loaded with less modern ones, they have to turn it on before launching or with the newer type, just after the initial stage detaches from the missile. This can potentially be very dangerous to pilots.
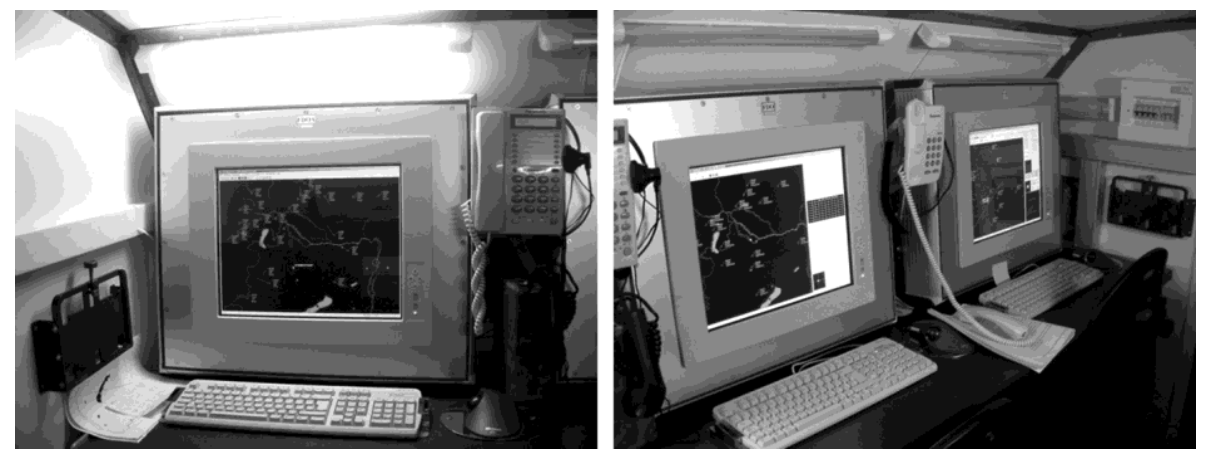

Picture 9. Workplaces of the FDC [7]

The three workplaces are - from left to right in the Picture $9-$ as follows: FDOA ${ }^{18}$, FDO and SM ${ }^{19}$. The FDO in the middle is always an officer in charge of the whole fire control activities. On the monitor he/she can see the RAP, integrated with LAP, the targets detected by local radars, the deployment places of subordinated fire units, their engagement footprint,

12 NATO - North Atlantic Treaty Organization

13 NATINADS - NATO Integrated Air Defence System

14 FDC - Fire Distribution Centre

15 FDO - Fire Distribution Officer

16 CRC - Control and Reporting Centre

17 TCP - Tactical Control Panel

18 FDOA - Fire Distribution Officer Assistant

19 SM - Sensor Manager 
their $\mathrm{RS}^{20}, \mathrm{ES}^{21}$ and so on. He/she has responsibilities listed below:

- "To identify air targets based on the NATO airspace control orders in force, the RAP, the electronic and visual identification capabilities of the fire units;

- To autonomously distribute fire between subordinate fire units in respect to air targets identified unambiguously as hostile, taking into consideration the capabilities of the fire units (the FDO workplace software supports this activity with automatically gen- erated proposals);

- To control the fire units' activities according to NATO FCOs (Fire Control Orders). "[4: 640]

The right hand side workplace is designed for SM. He/she has responsibilities see below:

- "To produce and maintain the LAP processing data of operational surveillance and height-finding radars;

- To produce the complex up-cleared air picture per correlating LAP and RAP;

- To introduce and control jamming and clutter filtering procedures by available prima- ry radar information displayed in digital form;

- To determine emission control by effective EMCON ${ }^{22}$ status and the available RAP;

- To supervise and control the radar crews

- To control the tactical relocation of surveillance radars meanwhile continuously main- taining the air picture." [4: 640]

The left hand side workplace is designed for FDOA. He/she has responsibilities listed below:

- "To input the effective $A C O^{23}$;

- To handle the deployment positions of fire units;

- To receive and input the orders ${ }^{24}$ (sending to subordinated fire units);

- To receive reports ${ }^{25}$ from fire units and to forward those to higher command post;

- To attend to objective control, keep the action log;

- To input and process the alerts $\left(A R W^{26}, N B C^{27}\right)$ and other messages. " [4: 641]

At fire unit level the $\mathrm{TCO}^{28}$ is the counterpart of the FDO in FDC. His/her workplace is in Straight Flush radar in front of the TCP workstation (you can see it in picture 8 right). On TCP "he/she can keep track of a computer synthetic air picture formed in the FDC, receives orders (SSTO and engagement) and sends reports to the FDC (SSREP and engagement)". [4: 641] The main advantages of this situation are that they receive air pictures to monitor the air situation and track targets so that they do not have to switch on their surveillance and target acquisition radars. They do not emit tell-tale radar radiation, as in the past, which im- proves their efficiency. "In automatic mode the equipment receives control signals from the universal interface device installed as a replacement of the old one that locks it on the target in elevation and azimuth.” [4: 641] In this way the crew can start the covering-engagement

20 RS - Readiness Status

21 ES - Emission Status

22 EMCON - Emission Control

23 ACO - Airspace Control Order

24 SSTO - SAM-SHORAD Tactical Order (SHORAD - Short Range Air Defence)

25 SSREP - SAM Status Report

26 ARW - Air Raid Warning

27 NBC - Nuclear, Biological and Chemical

28 TCO - Tactical Control Officer 
using television or thermal cameras which are parallel with target acquisition radar (see Pic- tures 5-7). Since the modernization of SA-6 Straight Flush radars in Poland, the Hungarian fire units have been disposed of secondary IFF radars, made by Ryatheon Company, type AN/ TPX-56. This equipment gives the last chance to TCO to identify the flying objects before giving the engagement order. "The solution guarantees every service necessary for modern high level automation, but needs no such modification in the original systems of the fire control radar that prevents its use in the conventional (before modernization) way." [4: 641]

\section{Conclusion}

This article wanted to give the reader a general picture about the development of SA-6 sys- tems in some countries, especially in Hungarian GBAD ${ }^{29}$, which has been performed during the last one and a half decades. Since Hungary joined NATO, it has been always clear to Air Force officers - especially to those who work for air defence — that our systems had to be able to work together in NATINADS/NATINAMDS ${ }^{30}$. At the moment we can say that our modernized system - using the K-1P Fire Distribution Cell with connected Tactical Control Panel that sends different orders, reports and Recognised Air Picture - is able to connect to higher echelon, and it is able to fulfil the requirements of the air defence community.

But now we cannot stop. Unfortunately — in some years — our missile stock is going to reach the end of its lifecycle. Nowadays no countries produce those types of missiles, which originally belonged to the SA-6 system, although, many different missiles with variants were produced. As it has been featured in this article, many attempts have been made in many countries all around the world to change these types of rounds to newer ones so as not to be forced to throw away the whole system and those soldiers who are trained to operate it properly.

So the main question for decision makers is to consider the whole situation. Hungari- an Defence Forces has only this type of radar guided GBAD system, which — because of its ageing missiles — in the early 2020s must be pulled out of service, or must be further developed to be able to use another type of missile, which can be bought and operated in a NATO environment. A different decision can be a procurement of an entirely new — at least in Hungary — GBAD system. If policy-makers make this decision, they must do it in a very short time, because those officers, $\mathrm{NCOs}^{31}$ who are $^{2}$ going to operate it must start their studies some years before the new system arrives in Hungary. They must consider if they want to have a conventional GBAD system or the type which has capabilities against ballistic missile threats, too. [8] In our unit we try do our best to give the most useful pieces of advice to our superiors in accordance with solving the problem.

29 GBAD - Ground Based Air Defence

30 NATINAMDS - NATO Integrated Air Missile Defence System

31 NCOs - Non-Commissioned Officers 
BOZSÓKI Attila: Developmental Trends in the SA-6 (2K12 KUB) Air Defence Missile Systems...

\section{References}

[1] KOPP, C. (2012): Legacy Air Defence System Upgrades. www.ausairpower.net/APA- Legacy-SAMUpgrades.html (downloaded: 2910 2013)

[2] SANDRU, V.: The Current Stage of Air Defense Systems' Structure and Performances.

S.A.M. Systems Comparative Analysis in Romanian Inventory. Review of the Air Force Academy, 123 (2013) www.afahc.ro/revista/Nr_1_2013/57\%20Vasile\%20Sandru.pdf (downloaded: 2910 2013)

[3] www.armyrecognition.com/idet_2011_daily_news_actualites_pictures_video/mbda_ and_retia_present_a_new_upgrade_version_of_the_russian_made_sa-6_gainful_at_ idet_2011_1005112.html (downloaded: 1102 2014)

[4] VARGA L.: New capabilities of the Hungarian Ground Based Air Defence Forces. AARMS 7 4 (2008) 633-645. www.hadtudomanyiszemle.zmne.hu/docs/Volume7/Issue4/pdf/05varg.pdf (downloaded: 2609 2013)

[5] www.wzu.pl/ (downloaded: 1102 2014)

[6] www.hmarzenal.hu/modules.php (downloaded: 1102 2014)

[7] MARKÓ I. (2012): Harcvezetési és tüzirányitási rendszerek. www.raketaezred.hu/index. php/rolunk/haditechnika/68-vezetesi-rendszerek (downloaded: 1202 2014)

[8] RUTTAI L., KRAJNCZ Z.: Hungary's possibilities in the development of NATO antiballistic missiles security system. AARMS 51 (2006) 69-74. www.zmne.hu/aarms/docs/ Volume5/Issue1/pdf/07rutt.pdf , (downloaded: 13 02 2014) 